\title{
DETECTING SEISMIC WAVES INDUCED BY BLAST OPERATIONS AT A LIMESTONE QUARRY BY MEANS OF DIFFERENT TRANSDUCER MOUNTING
}

\author{
G. COLTRINARI \\ Department of Engineering, University of Roma Tre, Rome, Italy
}

\begin{abstract}
The use of explosives to fragment the rock is very widespread in quarrying activities. This technology produces significant environmental impacts due to ground vibrations generated by blasting operations. In order to characterize this phenomenon, accurate measurements of seismic waves are required and one of the most critical aspects in field tests is represented by the coupling method between the transducers and the soil. This phenomenon may generate the distortion of the recorded waveform thus affecting the affordability of the sample itself. Moreover, the decoupling assumes a growing importance in those sites where the rock is not outcropping and the transducer is buried. For this purpose, different methods are tested in an opencast limestone quarry in the centre of Italy. Firstly, ground vibrations in terms of peak particle velocity (PPV) were recorded according with the method suggested in UNI 9,916 and consisting in burying the detectors into the soil at a suitable depth. Secondly, the same parameters were recorded by means of transducers fixed to the ground with some sand bags thus maintaining the proper adherence. Finally, the data obtained through these two different methods are compared and discussed. Keywords: ground transducer coupling, PPV, quarry blasting operations, seismic waves.
\end{abstract}

\section{INTRODUCTION}

Blasting operations in quarrying sites generate many unfavourable effects on the surrounding areas [1-3]. In particular, the most important impact factors resulting from quarrying activities regard phenomena like air blast noise [4], airborne dust [5], gas emissions [6] and ground vibrations $[7,8]$. Since quarry management have to demonstrate their compliance with legal requirements, in these sites, ground vibration monitoring is, generally, a routine activity. Although many national institutions developed specific documents or technical norms to define best practises and sampling methods $[9,10]$, the assessment of ground vibrations induced by blasting operations remains a complex activity because of many factors affecting seismic wave propagation. In particular, land subsidence and fracturing rather than soil characteristics may determine considerable alterations in ground movements. [11-13]. Furthermore, other parameters linked to blasting specifications influence the wave propagation and the connected ground vibration. Obviously, the characteristics of the explosive charge causing the release of energy is important but the spacing and the timing of the blasting operations may introduce a directional variation to the vibration. The burden of blast holes can have a significant influence on vibration levels: too much burden may increase ground vibration levels, too little burden in front row holes may result in flyrock and will increase air vibration levels. Moreover, when each hole is fired at a different time and from a different location, the resulting wave front could result strongly reinforced when 
the delay pattern is inappropriate, [14-16]. In order to provide appropriate sampling campaigns many guidelines define operational codes and practises. Among the others, the two most critical factors affecting the sampling phase are the placement of the vibration sensor (transducer) and its ground coupling. Many mounting methods are suggested by field guidelines [17] and many field studies have been carried out to test these options [18]. One of the common outcomes is that ground coupling of the transducer is comparable to a resonant system [19]. Poor coupling can cause distortion of the signal, altering its amplitude and phase, and often yielding higher measured vibration levels [20]. Some studies, aimed to point out the parameters influencing the resonant frequency, shown, by means of numerical models combined with field experiments, that the characteristics of the transducer like its weight and its base area were as relevant as the conditions of the soil, [21]. Other field tests [22] shown that the phase and amplitude of the vibrational signal were deeply influenced with the structure of the ground while the coupling resonance was found less dependent on change in mass or diameter of the transducer. This different outcome may be addressed to the great number of local parameters and boundary conditions influencing both the analytical models and experimental campaigns [23]. Real operational conditions are, in many cases, difficult to be modelled in a proper way according with analytical formulations, [24]. Most researchers and field guidelines agree that the best coupling, for high frequency recordings and when the maximum acceleration falls between 0.2 and $1.0 \mathrm{~g}$, can be achieved through the burying of the transducer $[25,26]$. Instead if the measurement surface consists of rock, concrete or asphalt the transducer should be fastened to the measurement surface through a bolt rather than with epoxy or any quick-setting material, for example rigid cement. Another ground coupling method of the transducer is the employment of spikes. Literature reveals that their use is a controversial and complex issue. Some authors claim that spikes can be an effective coupling system for evaluating ground acceleration below 1.0 $\mathrm{g}$ but others discourage their use claiming that they may affect the characteristics of the recorded movement. Furthermore, the measurements through spikes can overestimate the real ground vibration by a $46.5 \%$ factor [27]. Conversely, other researchers conclude that the burying of transducer or using long spikes are efficient ways of increasing the coupling resonance frequency. This point of view is not shared; a model developed, [8], shows that by increasing the spike radius and length, the frequency of resonance decreases. Another simple way of fixing a transducer to the ground is by placing a sandbag on its top. But also in this case there are different outcomes: some authors assert that the use of sand bags is a good method when the expected particle accelerations are below $1.0 \mathrm{~g}$. Conversely, other authors discourage their use. The above literature reveals inconsistency in what is the best way of coupling the sensor to the ground.

\section{MATERIAL AND METHODS}

This study is aimed to test and compare two different methods to record ground vibration by means of different coupling techniques. The sampling campaigns were carried out in a limestone quarry in the area of Rome. The first technique involves of burying the transducer while the second one is performed by means of sand bags whose weight helps to maintain the sensor in the correct setting. Being the propelled rock fragments beyond a specific limit, one of the most hazardous events in the open pit blasting operations, a no access area was defined during the blast operations and so on, it was not possible to characterize the source signal due the risk of damage to devices. Nevertheless the equipment utilized to characterize the source signal was capable of simultaneous readings. In particular, a direct reading of the maximum 
instantaneous peak particle velocity (PPV) (which is the vector sum of the three orthogonal ground vibration components detected by the instrument), was detected by means of a velocimeter while tri axial accelerometers measured ground vibration. The sampling points were positioned at a distance of $105 \pm 5 \mathrm{~m}$ from the blast hole (Fig. 1). The data collection consisted in samples from eight different blasts. Before each of them, the effectiveness of the ground transducer coupling was checked with an impulse to test if internal flaws had been introduced or significant ground differences could be appreciated. In order to reduce thermal errors, all field tests were carried out under the same boundary conditions. Finally, to capture the full blasting event at the measured distance, a recording time of 4 seconds was set.

\subsection{Sampling devices}

With regard to the sampling devices, a velocimeter and a triaxial accelerometer were supplied by the Engineering Department of Roma Tre University. The sampling frequency was 1,250 $\mathrm{Hz}$ for both instruments. The gain was $3.15 \mathrm{~V}$ for the tri axial accelerometer and $10 \mathrm{~V}$ for the velocimeter. In Table 1, the main characteristics of the devices are summarized.

The right alignment of the transducer with respect to the ground is very important to obtain correct measurements. A defective alignment may, in fact, lead to an obvious measurement error. The sensor must be nearly leveled on the ground and few degrees of inclination may generate errors in detecting signals. Moreover scientific literature suggested that below $60 \mathrm{~Hz}$ amplitude, the distortion of signal is more influenced by the vertical alignment of the transducer than it is to by the coupling mechanism. Being this frequency range, the main area of interest of this study, before each test the vertical and horizontal correct alignment with respect to the ground was verified. The correct position of the velocimeter was checked by mean of screws fixed on the instrument base. The correct placement of the tri axial accelerometer was otherwise checked with a bubble level.

\subsection{First measurement campaign}

In order to investigate the ground-to-transducer planting mechanism, the first measurement campaign was carried out according to the cited guidelines $[9,10]$. In the range of acceleration exceeding $1 \mathrm{~g}$, the burial of the transducer is the recommended method which minimizes the ground coupling distortion. The procedure consists of realizing the cavity of suitable dimensions; two holes of similar depth $(50 \pm 5 \mathrm{~cm})$ were excavated at a distance of $150 \mathrm{~cm}$ from each other as shown in Fig. 2. In order to minimize the risk of slippage and so performing a good coupling with the ground, the hole was refilled with the excavated material and then it was hand-compacted around the sensor as shown in Fig. 3.

This methodology allowed a good coupling mechanism between the sensor and the ground. Moreover, because of the mechanical strength of the rock, a wrecker hammer was utilized to

Table 1: Characteristics of measuring equipment.

\begin{tabular}{lccc}
\hline Transducer & Sensitivity & Sampling Frequency $[\mathrm{Hz}]$ & Gain $[\mathrm{V}]$ \\
\hline Tri axial accelerometer & $10.55\left[\mathrm{mV} /\left(\mathrm{m} / \mathrm{s}^{2}\right)\right]$ & 1,250 & 3.15 \\
PCB 393A03 & & & \\
3D Sinus Seismometer & $27\left[\mathrm{mV} /\left(\mathrm{mm} / \mathrm{s}^{-1}\right)\right]$ & 1,250 & 10 \\
\hline
\end{tabular}




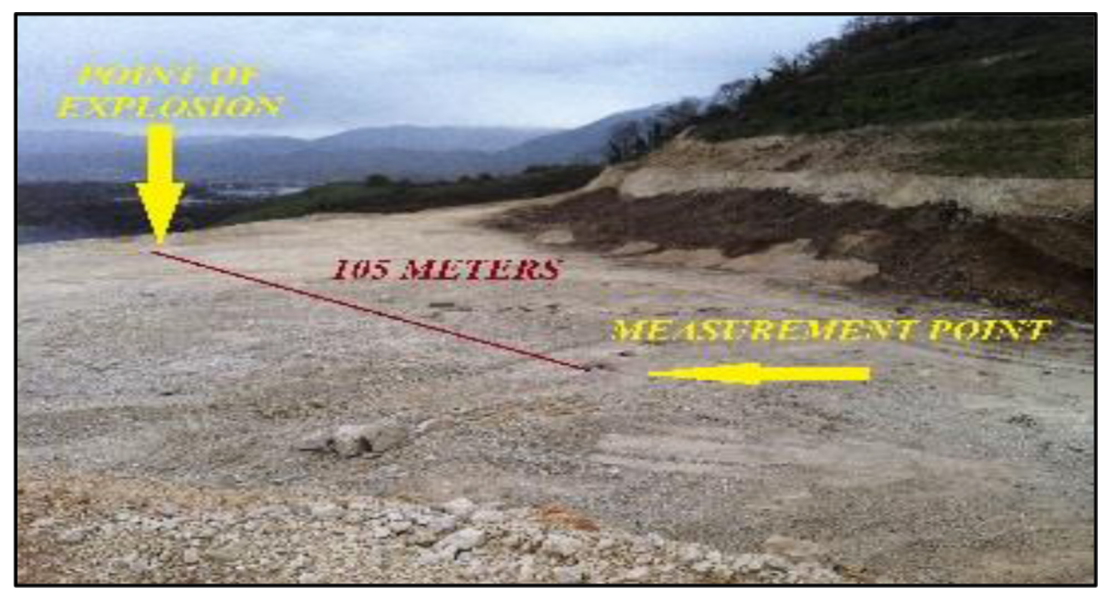

Figure 1: The measurement site.
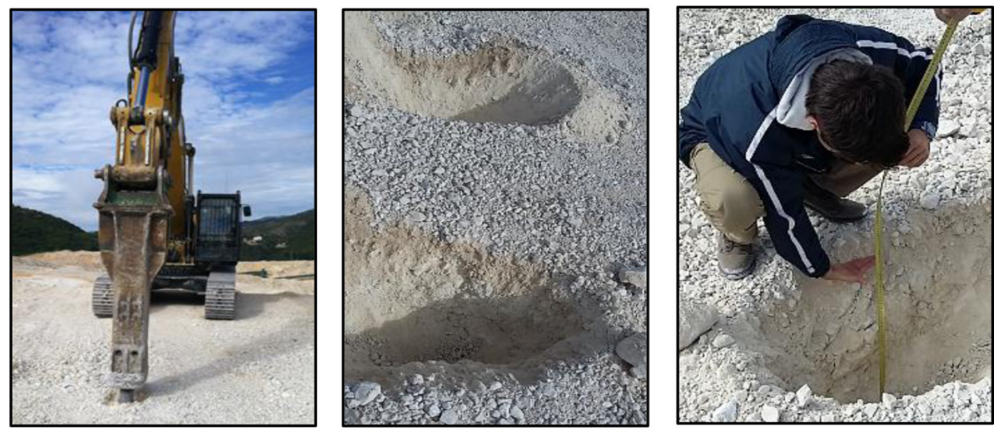

Figure 2: Excavation of the two holes for burying the transducers.
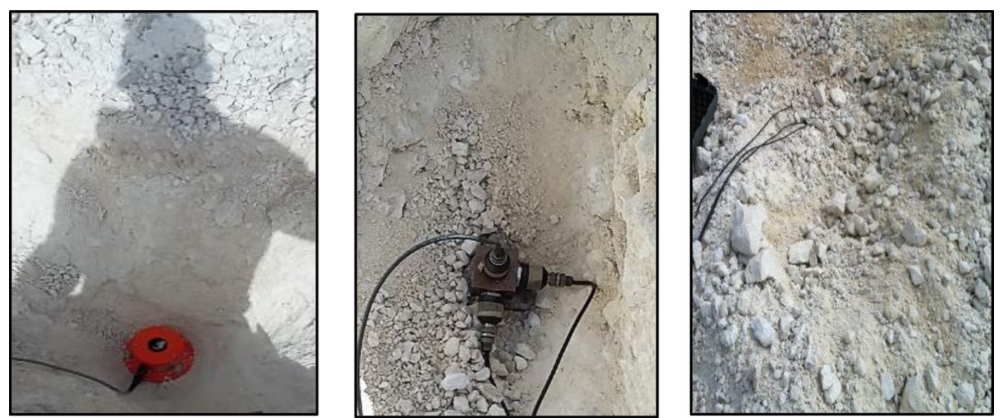

Figure 3: Positioning of transducers (left and central figure) and their burying (right figure).

excavate the holes thus determining some fractures around the holes. Although these fractures could generate an insertion error, this last was assessed as a systematic one and quantified as constant not affecting the reliability of the reading. The instruments have been positioned according to the same standard reference system; $\mathrm{x}$-axis = perpendicular to the explosion point (longitudinal), $\mathrm{y}$-axis = orthogonal to $\mathrm{x}$-axis (transversal), $\mathrm{z}$-axis $=$ perpendicular to the ground (vertical). 


\subsection{Second measurement campaign}

As described above, another simple way of fixing a transducer to the ground is by placing a sand bag on its top as shown in Fig.4. The second measurement campaign was carried out according to this methodology. Every bag has been positioned on the top of each device to ensure a good coupling transducer-ground, without changing the alignment of the instrument respect to soil.

As in the first measurement campaign, the instruments were placed at the same distance of 105 metre from the blast hole.

\section{RESULTS}

The following graphs show the results obtained from the two measurement campaigns. As previously described, the data are obtained through two methods of transducer-ground coupling; in the first campaign the transducer has been buried while in the second one a stone sack has been positioned on the top of the instrument.

\subsection{First measurement campaign}

The data are referred to the same blasting operation. In Fig. 5, the time history graphs, expressed in terms of $\mathrm{mm} / \mathrm{s}$, are shown for the buried velocimeter for the three axes, while in Fig. 6 the corresponding frequency spectra are reported.
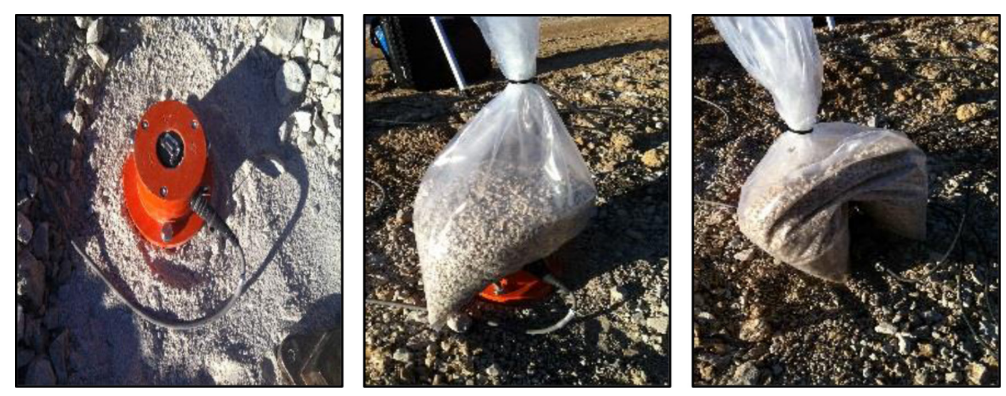

Figure 4: Sacks of limestone material on the top of transducers.

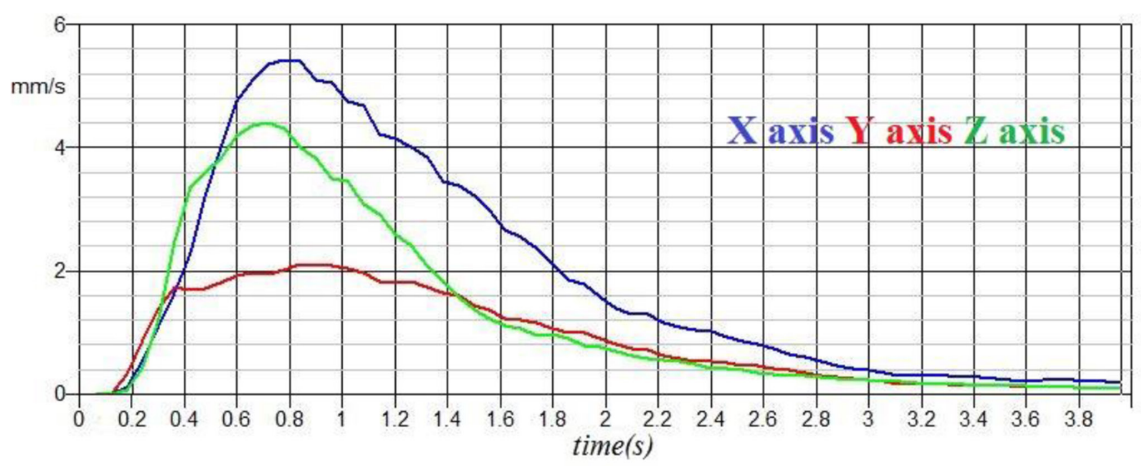

Figure 5: Time history resulting from buried velocimeter. 


\subsection{Second measurement campaign}

Results from the second campaign are shown in the following graphs. In Figs 7 and 8 time history and frequency spectra are shown. All data are expressed in terms of mm/s.

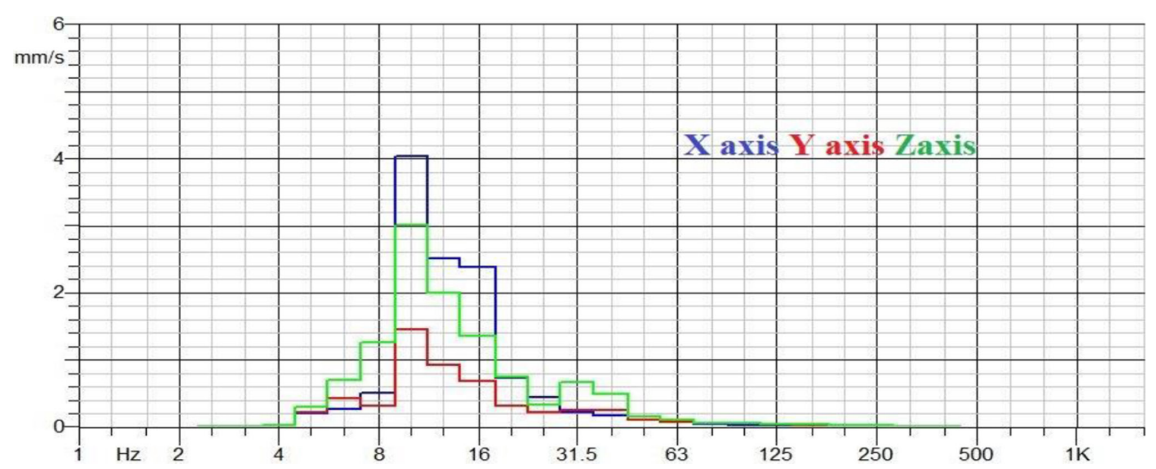

Figure 6: Frequency spectrum from buried velocimeter.

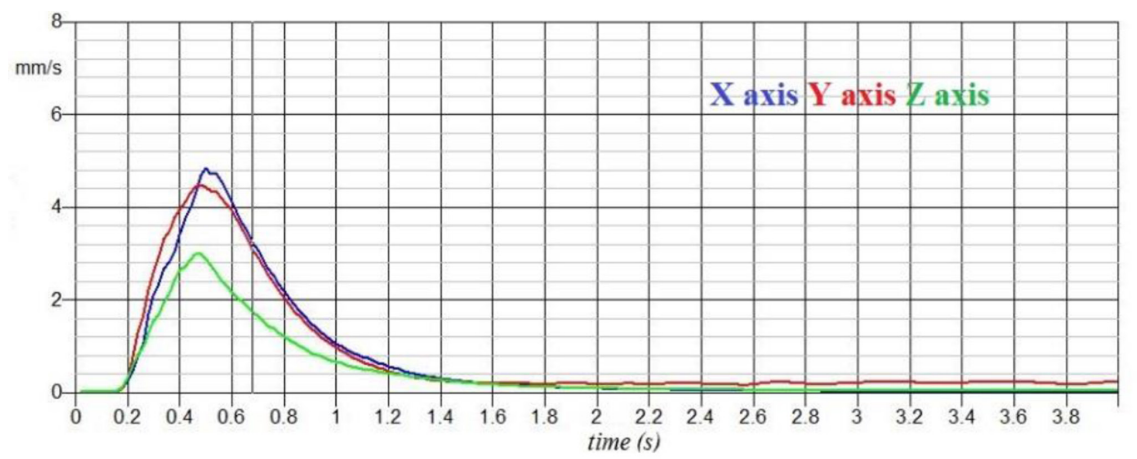

Figure 7: Time history of accelerometer fixed with sand bags.

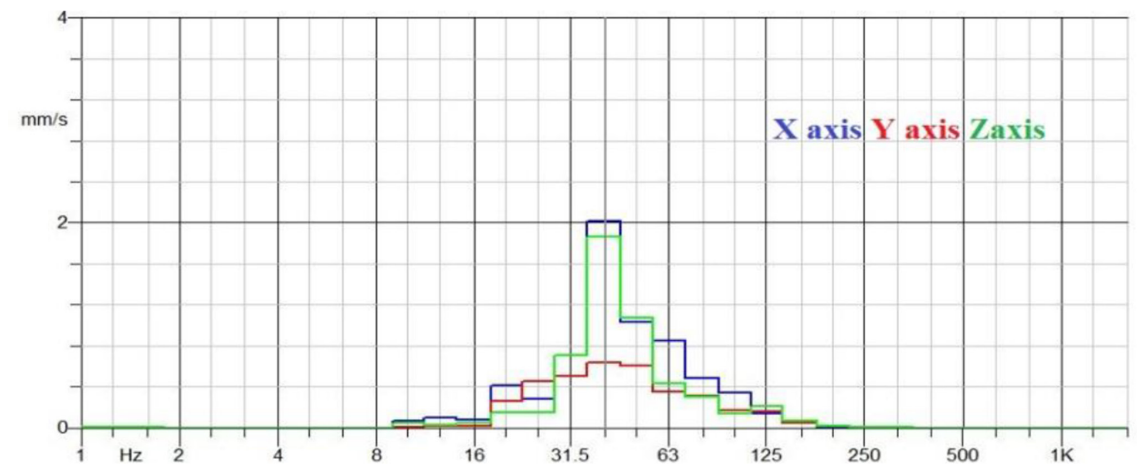

Figure 8: Frequency spectrum of accelerometer fixed with sand bags. 


\section{DISCUSSION}

The data were carried out from eight blasts. For each blasting operation, particle velocities and the dominant frequencies are obtained for the longitudinal, transversal and vertical components of ground motion. The PPV has been assessed from the waveform as the maximum instantaneous value of the vector sum of the three orthogonal ground vibration components. In many cases, the PPV value may be observed when one of the three vector components show its maximum value. However, the dominant frequency is determined as the frequency at which the spectral amplitude, derived through fast Fourier Transform Analysis, is maximum. Furthermore, the pseudo-vector sum (MAX PPV) has been calculated as the sum of maximum values for each component, independently of temporal instant. Table 2 shows the recorded data for each mounting method. Columns on the left show values of PPV, MAX PPV and the corresponding percentage differences. The other columns show the values of frequency along each direction.

Table 2: Accelerometer results.

\begin{tabular}{llllll}
\hline \multicolumn{5}{c}{ Buried Accelerometer } \\
\hline PPV & MAX PPV & $\Delta \%$ & $\mathbf{X}[\mathbf{H z}]$ & $\mathbf{Y}[\mathbf{H z}]$ & $\mathbf{Z}[\mathbf{H z}]$ \\
\hline 8.99 & 9.38 & 3.53 & 8 & 8 & 8 \\
9.33 & 9.43 & 1.05 & 10 & 16 & 10 \\
7.19 & 7.26 & 1.01 & 10 & 10 & 10 \\
14.94 & 15.19 & 1.61 & 20 & 16 & 20 \\
13.64 & 13.84 & 1.49 & 25 & 25 & 25 \\
\hline \multicolumn{7}{c}{ Accelerometer fixed with sand bag } \\
\hline 5.30 & 5.71 & 7.27 & 25 & 25 & 25 \\
4.62 & 4.68 & 1.36 & 40 & 40 & 40 \\
11.30 & 12.25 & 7.75 & 31.5 & 25 & 31.5 \\
\hline
\end{tabular}

Table 3: Velocimeter results.

\begin{tabular}{lccccc}
\hline \multicolumn{5}{c}{ Buried Velocimeter } \\
\hline PPV & MAX PPV & $\Delta \%$ & $\mathbf{X ~ [ H z ]}$ & Y [Hz] & $\mathbf{Z}[\mathbf{H z}]$ \\
\hline 8.83 & 9.78 & 9.69 & 8 & 8 & 8 \\
9.34 & 10.10 & 7.59 & 50 & 50 & 40 \\
7.75 & 7.77 & 0.30 & 10 & 10 & 10 \\
14.35 & 14.67 & 2.18 & 20 & 16 & 20 \\
12.44 & 12.68 & 1.89 & 25 & 25 & 25 \\
\hline \multicolumn{7}{c}{ Velocimeter fixed with sand bags } \\
\hline 5.70 & 5.75 & 0.90 & 25 & 25 & 25 \\
4.26 & 4.81 & 1.49 & 40 & 40 & 40 \\
10.86 & 11.24 & 1.92 & 31.5 & 31.5 & 31.5 \\
\hline
\end{tabular}


Table 4: Results in terms of PPV percentage.

\begin{tabular}{lll}
\hline Method & \multicolumn{1}{c}{$\Delta \% \mathrm{PPV}$} & $\Delta \% \mathrm{M} \mathrm{PPV}$ \\
\hline Buried & 1.79 & -4.24 \\
Buried & -0.05 & -7.14 \\
Buried & -7.71 & -6.94 \\
Buried & 3.98 & 3.42 \\
Buried & 8.79 & 8.41 \\
Sack & -7.60 & -0.69 \\
Sack & 7.84 & -2.79 \\
Sack & 3.92 & 8.26 \\
\hline
\end{tabular}

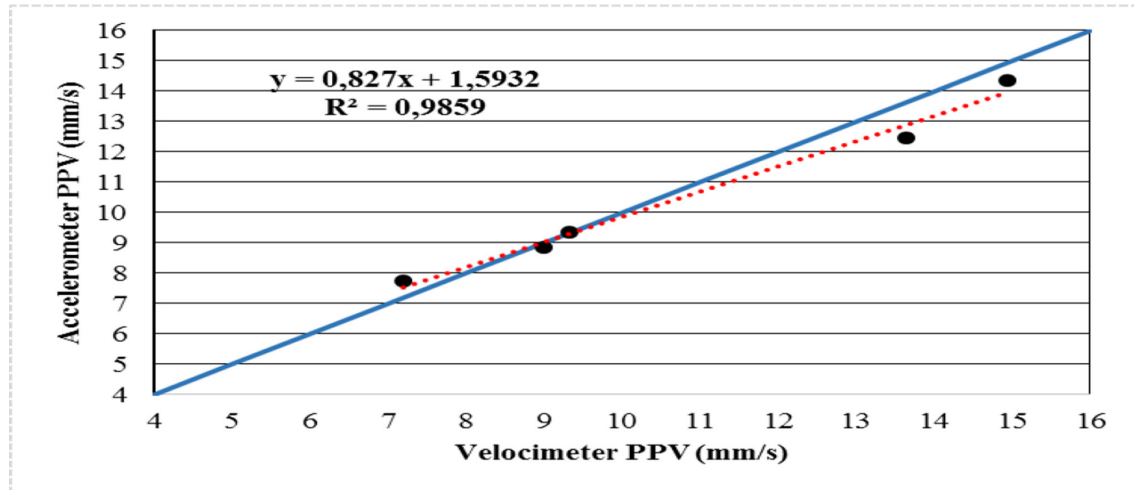

Figure 9: Trend of PPV values for both instruments.

Data show that, in almost every measurement, $\mathrm{X}$ is the direction of greater stress (see Fig. 1). This outcome may be appreciated by analysing the results from both the velocimeter and the accelerometer. Moreover, as shown by the values in the previous Table 3, the differences in terms of percentage between the values of PPV and those of PPV MAX are less than $2 \%$. In only two blast events, the response of the velocimeter is higher by a factor between $7 \%$ and $10 \%$. In order to highlight the data of PPV obtained from the two measurement campaigns they were collected in the same table and a unique graph, as shown in the following figures. The Table 4 shows the percentage differences between PPV values obtained from velocimeter and accelerometer.

In order to test the differences between the two sets of values and hence the two methodologies, the same technique often utilized to assess differences between different sampling devices $[28,29]$ is adopted. So a correlation analysis is presented, a Pearson product-moment correlation coefficient (PPMCC) is evaluated and a linear regression is modelled according to the expression shown in the following figure where results are presented. The scatterplot shows a good strength of linear correlation $\left(R^{2}=0.985\right)$, although a bias may be observed.

\section{CONCLUSIONS}

This study examined a comparative performance test of two different transducer mounting techniques under the particular conditions found in a limestone quarry in Italy. The most 
interesting response of the sampling campaign may be focused on the outcome regarding the most stressed direction. In particular in the most cases of the recorded blasting events the $\mathrm{x}$-axis (the longitudinal one) was the most stressed and in only two cases the $\mathrm{z}$ direction (the orthogonal direction to the ground) was found to be coincident with the direction of maximum propagation of the waveform. Moreover, in spite of a limited number of available measurements, the accelerometer readings were observed to be higher than those from velocimeter when referred to lower PPV values. On the contrary a possible underestimation may be observed in the higher range of recorded PPV values. Nevertheless the analysis of the scatterplot between the two sets of values (velocimeter and accelerometer) together with the line of tendency, suggests a strict correlation.

These results strongly encourage further research with further measurement campaigns, under the same boundary conditions to improve the accuracy of measurements. The way in order to obtain this aim may involve the use of coupling the transducers to the ground by means of iron spikes fixed into the soil. Currently is under investigation the hypothesis of coupling the transducers to the ground by means of iron spikes.

\section{REFERENCES}

[1] Phang, M.K., Simpson, T.R. \& Brown, R.C., Investigation of Blast-Induced Underground Vibrations from Surface Mining, University of Alabama, Mineral Resources Institute, 1984.

[2] Singh, P.K. \& Roy, M.P., Damage to surface structures due to blasting. International Journal of Rock Mechanics and Mining Sciences, 47(6), pp. 949-961, 2010. http://dx.doi.org/10.1016/j.ijrmms.2010.06.010

[3] Cardu, M., Giraudi, A., Lovera, E. \& Michelotti, E., An example of preliminary seismic survey to evaluate the feasibility of blasting works in proximity of a sensitive monument, Vienna Conference Proceedings, ed. P. Moser et al., European Federation of Explosives Engineers, ISBN 978-0-9550290-1-1, 2007.

[4] Mishra, A.K. \& Sinha, M., Environmental impact analysis of heavy blasting in large opencast mines. Journal of Mines, Metals and Fuels, 63(7), pp. 173-181, 2015.

[5] Alfaro Degan, G., Di Bona, G., Lippiello, D. \& Pinzari, M., PM10 dispersion model in quarrying activities, a comparison of an ISC3 approach to a mono/multivariate geostatistical estimation. WIT Transactions on Ecology and the Environment, 86, pp. 111-120, 2006, ISSN 1743-3541. http://dx.doi.org/10.2495/AIR06012

[6] Călămar, A., Pupăzan, D., Găman, G.A., Kovacs, M. \& Simion, S., Study regarding the environmental impact of gases generated by pit blasting operations. Proceedings of International Multidisciplinary Scientific GeoConference Surveying Geology and Mining Ecology Management, SGEM 2015, 1(5), pp. 831-838, 2015.

[7] Siskind, D.E., Stagg, J., Kopp, J.W. \& Dowding, C.H., Structure response and damage produced by ground vibrations from surface mine blasting, USBM Report of Investigation 8507, Twin Cities: U.S. Bureau of Mines, 1980.

[8] Singh, P.K. \& Vogt, W., Ground vibration: prediction for safe and efficient blasting. Zukunft mit Tiefgang, Erzmetal, pp. 677-684, 1998.

[9] AENOR., Control de vibraciones producidas por voladuras, UNE 22-381-93, Asociación Española de Normalización y Certificación: Madrid, 1993.

[10] DIN., Deutsches Institut fur Nurmung. DIN 45669-2:2005-6: Measurement of vibration immission Part 2: Measuring method, Berlin, 2005. 
[11] Gutowski, T.G. \& Dym, C.L., Propagation of ground vibration: a review. Journal of Sound and Vibration, 49(2), pp. 179-193, 1976.

http://dx.doi.org/10.1016/0022-460X(76)90495-8

[12] Alfaro Degan, G., Lippiello, D., Lorenzetti, S. \& Pinzari, M., Vibration assessing models: comparison between methods. WIT Transactions on Biomedicine and Health, 16, pp. 59-69, 2013, ISSN: 1743-3525.

http://dx.doi.org/10.2495/EHR130061

[13] Cardu, M., Oreste, P., Pettinau, D. \& Guidarelli, D., Automatic measurement of drilling parameters to evaluate the mechanical properties of soils. American Journal of Applied Sciences, 10(7), pp. 654-663, 2013. http://dx.doi.org/10.3844/ajassp.2013.654.663

[14] Kahriman, A., Analysis of parameters of ground vibration produced from bench blasting at a limestone quarry. Soil Dynamics and Earthquake Engineering, 24, pp. 887892, 2004.

http://dx.doi.org/10.1016/j.soildyn.2004.06.018

[15] Segarra, P., López, L.M. \& Sanchidrián, J.A., Uncertainty in measurements of vibrations from blasting. Rock Mechanics and Rock Engineering, 45(6), pp. 1119-1126, 2012. http://dx.doi.org/10.1007/s00603-012-0229-y

[16] Kima, D.S. \& Lee, J.S., Propagation and attenuation characteristics of various ground vibrations. Soil Dynamics and Earthquake Engineering, 19, pp. 115-126, 2000. http://dx.doi.org/10.1016/S0267-7261(00)00002-6

[17] BSI, British Standards Institution, BS 7385-1: Evaluation and measurement for vibration in buildings, Part 1: Guide for measurement of vibrations and evaluation of their effects on buildings, London, 1990.

[18] Segarra, P., Sanchidrián, J.A., Castedo, R., López, L.M. \& Castillo, I.D., Performance of some coupling methods for blast vibration monitoring. Journal of Applied Geophysics, 112, pp. 129-135, 2015.

http://dx.doi.org/10.1016/j.jappgeo.2014.11.012

[19] Washburn, H. \& Wiley, H., The effect of the placement of a seismometer on its response characteristics. Geophysics, 6, pp. 116-131, 1941.

http://dx.doi.org/10.1190/1.1443713

[20] Krohn, C.E., Geophone ground coupling. Geophysics, 49(6), pp. 722-731, 1984. http://dx.doi.org/10.1190/1.1441700

[21] Omata, S., Ground couplings and measurement frequency ranges of vibration transducers. Journal of the Acoustical Society of America, 73(6), pp. 2187-2192, 1983. http://dx.doi.org/10.1121/1.389543

[22] Hoover, G.M. \& O'Brien, J.T., The influence of the planted geophone on seismic land data. Geophysics, 45, pp. 1239-1253, 1984. http://dx.doi.org/10.1190/1.1441121

[23] Drijkoningen, G.G., Rademakers, F., Slob, E.C. \& Fokkema, J.T., A new elastic model for ground coupling of geophones with spikes. Geophysics, 71(2), pp. Q9-Q17, 2006. http://dx.doi.org/10.1190/1.2187777

[24] Faber, K., Maxwell, P.W. \& Edelmann, H.A.K., Recording reliability in seismic exploration as influenced by geophone-ground coupling. 56th Meeting of the EAEG, Vienna, 1994. 
[25] Dowding, C.H., Suggested method for blast vibration monitoring. International Journal of Rock Mechanics and Mining Sciences \& Geomechanics, 29(2), pp. 145-156, 1992. http://dx.doi.org/10.1016/0148-9062(92)92124-U

[26] Stagg, M.S. \& Engler, A.J., Measurement of blast-induced ground vibrations and seismograph calibration, US Bureau of Mines (RI 8506), 1980.

[27] Blair, D.P., Blast vibration in soil and on large resonant structure. Explo'95, Conference, Brisbane, Australia, pp. 317-322, September 1995.

[28] Alfaro Degan, G., Lippiello, D. \& Pinzari, M., Monitoring airborne dust in a Italian basalt quarry: comparison between sampling methods. WIT Transactions on Ecology and the Environment, 174, pp. 75-84, WIT Press, 2013, ISSN 1743-3541. http://dx.doi.org/10.2495/AIR130071

[29] Alfaro Degan, G., Lippiello, D. \& Pinzari, M., Field evaluation of PM10 detectors in a quarry environment. International Journal of Sustainable Development and Planning, 10(3), pp. 361-372, 2015.

http://dx.doi.org/10.2495/SDP-V10-N3-361-372 